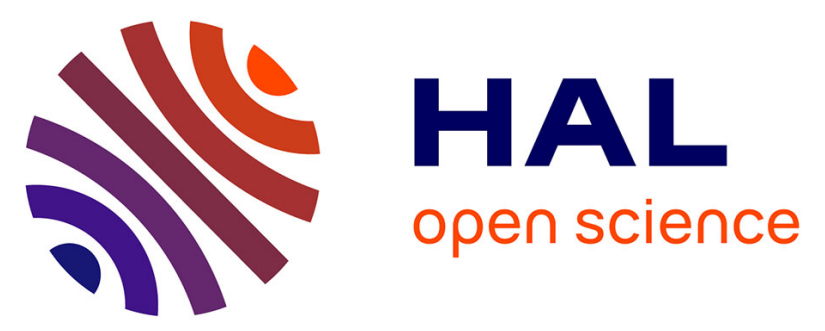

\title{
Using Hyperspectral Remote Sensing Identification of Wheat Take-All Based on SVM
}

Hongbo Qiao, Hongtao Jiao, Yue Shi, Lei Shi, Wei Guo, Xinming Ma

\section{To cite this version:}

Hongbo Qiao, Hongtao Jiao, Yue Shi, Lei Shi, Wei Guo, et al.. Using Hyperspectral Remote Sensing Identification of Wheat Take-All Based on SVM. 8th International Conference on Computer and Computing Technologies in Agriculture (CCTA), Sep 2014, Beijing, China. pp.23-30, 10.1007/978-3319-19620-6_3. hal-01420250

\section{HAL Id: hal-01420250 \\ https://hal.inria.fr/hal-01420250}

Submitted on 20 Dec 2016

HAL is a multi-disciplinary open access archive for the deposit and dissemination of scientific research documents, whether they are published or not. The documents may come from teaching and research institutions in France or abroad, or from public or private research centers.
L'archive ouverte pluridisciplinaire HAL, est destinée au dépôt et à la diffusion de documents scientifiques de niveau recherche, publiés ou non, émanant des établissements d'enseignement et de recherche français ou étrangers, des laboratoires publics ou privés. 


\title{
Using Hyperspectral remote sensing Identification of wheat Take-all based on SVM
}

\author{
Hongbo Qiao ${ }^{\mathrm{a}}$, Hongtao Jiao ${ }^{\mathrm{b}}$, Yue Shi ${ }^{\mathrm{c}}$, Lei Shi ${ }^{\mathrm{d}}$, Wei Guo ${ }^{\mathrm{e}}$,Xinming $\mathrm{Ma}^{\mathrm{f}}$ \\ College of information and management science, Henan Agriculture University, \\ Zhengzhou,450046,China; \\ aiaohb@126.com, ${ }^{\mathrm{a}}$ python.jiao@gmail.com, ${ }^{\mathrm{c}}$ 353303543@qq.com, ${ }^{\mathrm{d}}$ sleicn@126.com, ${ }^{\mathrm{e}}$ \\ guoweiworkhome@126.com, ${ }^{f}$ xinmingma@126.com
}

\begin{abstract}
Wheat take-all is quarantine diseaseand took place more and more severer in recent years, It is important to monitor it effectively. This article using hyperspectral remote sensing, through the different levels of the incidence of wheat take-all canopy spectral reflectance data collection analysis and processing, using support vector machine(SVM) classification method to build Wheat Take-all disease level prediction model for the prediction and prevention for wheat take-all to provide technical support. Results shows that the wheat canopy spectral reflectance change significantly under the influence of the disease; through data analysis, choose 700 900nm wavelength band training as sensitive to model the performance of the best results; Upon examination, constructed the forecasting model based on this band to predict when the predicted value and the actual value of the correlation coefficient up to 0.9434 . The results of this study will not only provide theoretical and technical support for wheat no-destructive detection and safety production, but also shed light on the development of novel strategy to detect and control crop pest and disease, which has great significance to the food safety.
\end{abstract}

Keywords: Wheat; Wheat Take-all; hyperspectral; support vector machine; forecasting model

\section{Introduction}

Wheat is China's major grain crops, Invasion by the diseases of wheat in the growth process, resulting in lower yields, even crops. Wheat Take-all is quarantine disease by soil-borne. In recent years, with the transport seeds and combined harvest, there is increasing trend occurred in our country. Therefore, analysis and research on wheat canopy spectral reflectance analysis of the differences in different Wheat Takeall disease infestation level in different canopy reflectance, Establishment of wheat take-all prediction models for large-scale Wheat Take-all prediction and prevention is important. Crops affected by different levels of disease stress because of their cell structure, pigment, water, nitrogen content and external shape changes result in changes in canopy spectra, for use fast hyperspectral remote sensing technology, predicted a large area of wheat take-all disease possible. Currently, some domestic scholars use hyperspectral remote sensing technology for species identification and recognition of crop disease research; Liu et.al using hyperspectral data for fir and 
Masson pine identify research, by extracting the important feature of the band to complete the fir and Masson pine classification ${ }^{[1]}$. Xiu et.al using hyperspectral technology to identify rice cadmium pollution, establish a model to predict the cadmium content in rice ${ }^{[2]}$. Wang et.al using hyperspectral wheat stripe rust infestation level classification study to conduct of the study laid the theoretical foundation and reference ${ }^{[3-10]}$. Summary, we can build wheat canopy spectral reflectance and diseases rank correlation model, previous studies of the spectral data processing methods are classified by traditional statistical or neural networks algorithm, etc, which are not able to better handle large, complex multi-dimensional data. In this study, by using support vector machine technology for classification, it can better solve these problems. This study selected a different wheat take-all levels wheat experiment, Observed under different disease severity, wheat canopy spectral characteristics, By selecting the optimal parameters and kernel function to complete the training classification of spectral data and build predictive models, and provide a theoretical basis and technical support for further use of hyperspectral remote sensing to predict wheat take-all levels.

\section{Materials and Methods}

\subsection{Data Collection}

We collect data by using ASD FieldSpec FR, this device can continuous measurement wavelength in the range of $325 \sim 1075 \mathrm{~nm}$, and select the measurement time in fine weather, no wind, no clouds 10:00 - 14:00 noon (solar elevation angle greater than 45 degrees). Before measurement, preheat the instrument should be set under natural light for 20 minutes, then the instrument calibration standard white, ground spectral measurements in natural light conditions, fiber optic probe vertically downward, with the canopy to keep the measured distance of $50 \mathrm{~cm}$ and probe beneath the area to ensure that no shadows. Each sample collecting 10 spectral curve, after taking an average of these spectral curve as a representative curve, the instrument must be done before each measurement to optimize and make a standard white calibration. In this study, we collected 25 samples, and each sample collecting 10 spectral curve to researching. In 2012, April 21, 2013 and May 16 on wheat canopy spectra were measured.

\subsection{Data analysis and processing}

In order to improve the stability and adaptability experiment, pretreatment raw spectral data by using data processing software ASD ViewSpec Pro 6.0.1. Taking an average of each sample spectral curve as a representative curve.

In this study, support vector machine approach to training data classification, support vector machine (SVM) to deal successfully with a small sample of training data set and produce higher classification accuracy, which has been widely used in pattern recognition[10-12]. The key is to choose SVM classification kernel function 
and parameters C and Gama (parameter g). Finally we using Matlab7.14 and Taiwan Professor Zhiren Lin Libsvm development kit combines training data to build predictive models.

\section{Results and analysis}

\subsection{Wheat Take-all Disease canopy spectral reflectance characteristics}

Wheat canopy spectral relatively easy to measure, and less affected by atmospheric effects and directly reflect the spectral characteristics of the victim status of wheat. Figure 1 shows, in the infrared spectral reflectance of $400 \sim 700 \mathrm{~nm}$ trend is not obvious, due to physiological changes in the structure of the incidence of wheat caused plants containing chlorophyll, water, nitrogen and the cell structure is changed, the light absorption and reflection with the normal difference, in particular in the range of $700 \sim 900 \mathrm{~nm}$ (Figure 2), increasing the spectral reflectance with disease severity decreased.

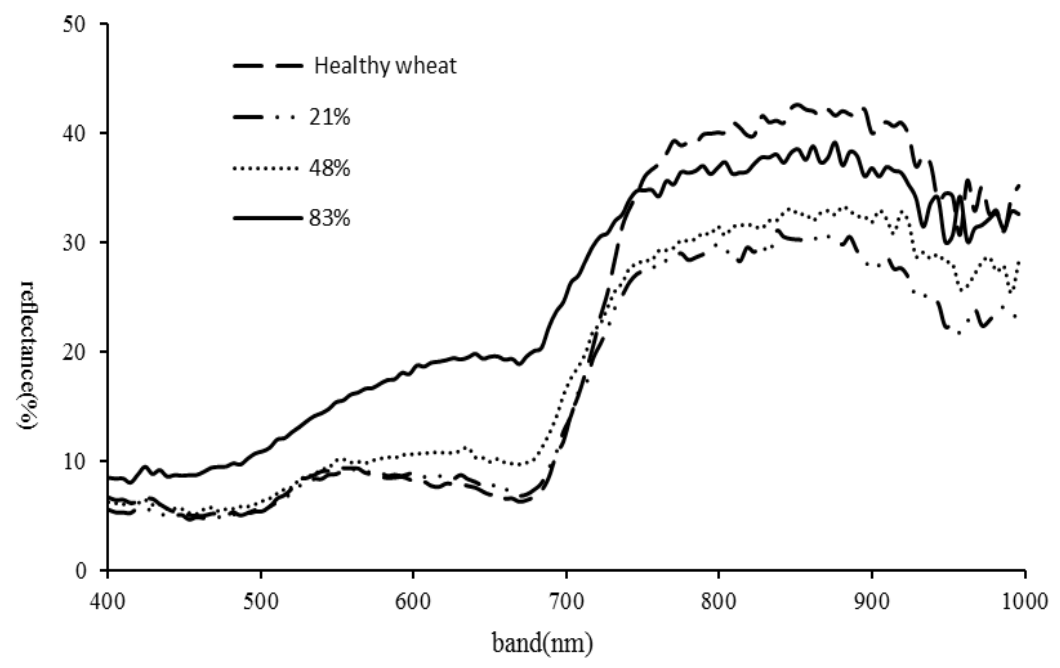

Fig. 1. Normal wheat canopy spectral curve comparison with diseases of wheat 


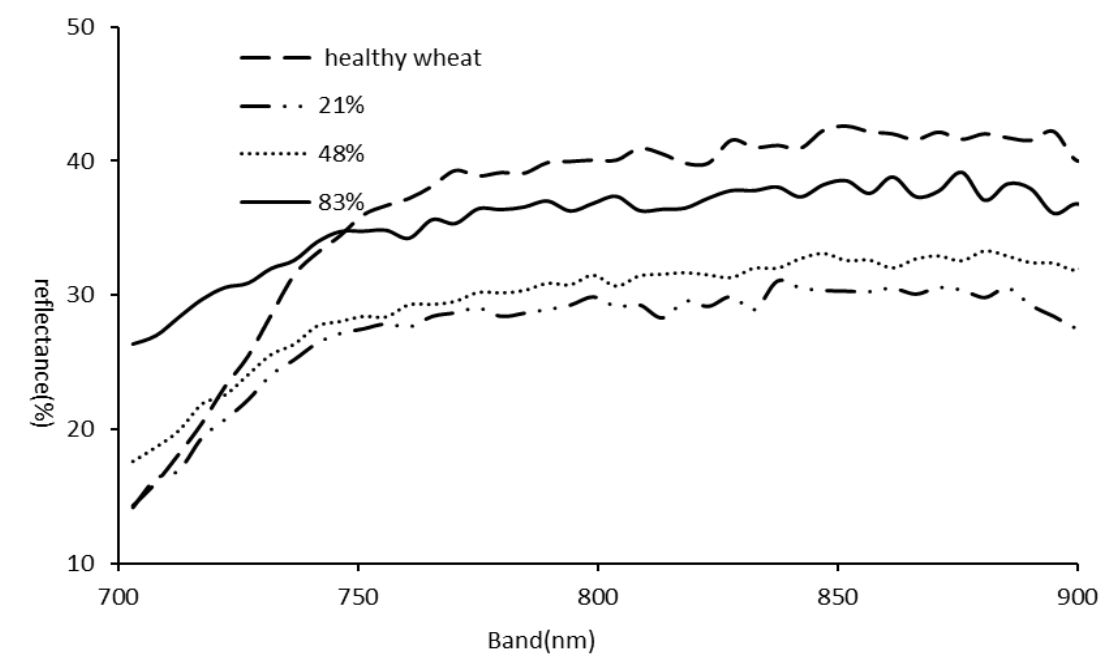

Fig. 2. comparison reflectance spectrum at $700 \sim 900 \mathrm{~nm}$

\subsection{Canopy spectral reflectance characteristics of different degrees of Wheat Take-all Disease}

Figures 1 and 2 show that in the infrared range of 400 700nm, the victim canopy reflectance and canopy reflectance curve of normal growth over the same period the basic agreement, and in the near infrared wavelength range 700 900nm, Wheat Take-all disease of spectral reflectance changed significantly, with the aggravation of the disease, canopy reflectance decreased significantly. Therefore, by wheat canopy spectral changes in the range of 700 900 $\mathrm{nm}$ to predict wheat Take-all disease hazard rating possible. According to the spectral variation in this band, Wheat Take-all disease will be divided into four grades, followed by health, minor, serious, very serious four grades. In the range of $700 \sim 900 \mathrm{~nm}$, wheat spectral change significantly with different levels of Wheat Take-all disease, therefore, this range can be extracted as a sensitive band, this band data as training data to build predictive models.

\subsection{SVM Model Building and Parameter Optimization}

By analyzing the relationship between Wheat Take-all disease and canopy spectral reflectance. The results showed (Fig. 2), in the range of 700 900nm, Wheat Take-all disease and canopy spectral reflectance correlation is particularly significant. Therefore, this band can be selected as sensitive bands, extracting this data within the band as the feature data, the test will be extracted from the data and use the difference between the ratio of peaks and valleys as training data to build the model, is better than using the original training data, so use this method for all sample data processing. 
Build models need to select the appropriate kernel function and the optimal parameters, we using cross-validation method to select the optimal parameters, and select the application more widely RBF kernel function ${ }^{[13-15]}$. The May 2013 data as training data for all samples, randomly selected in the same period in 2012 as a validation of the five groups of data, using Matlab and Libsvm toolbox training the best parameters $\mathrm{C}$ and Gama (parameter $\mathrm{g}$ ) as shown in Figure 3, and using the best parameter and radial basis function to create predictive models ${ }^{[16-18]}$.

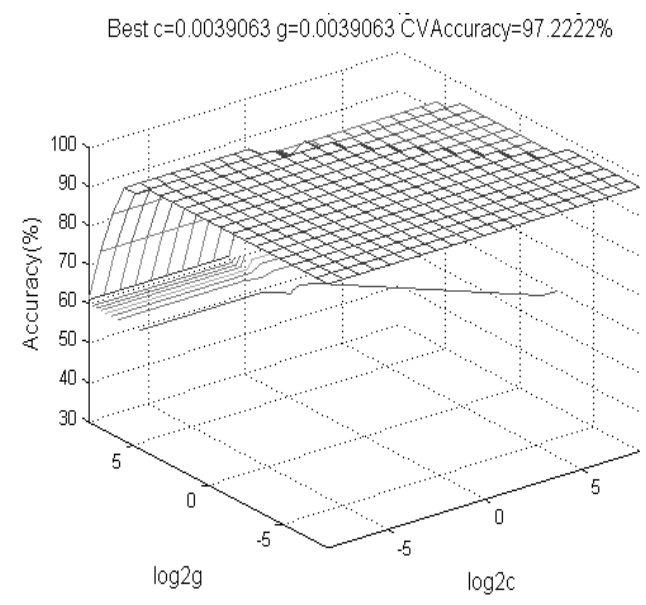

Fig. 3. By Matlab and Libsvm to find the optimal parameters $\mathrm{C}$ and $\mathrm{g}$.

\subsection{The accuracy of prediction model}

Using Libsvm toolbox svm-predic forecasting tool to predict the five sets of unknown data, and analyzing the correlation between predicted and actual values to verify the accuracy of the model. The May 2013 data for all samples as training data for training, and all of the 2012 data in May as the validation sample data, different bands were selected as the training data as sensitive bands, different optimal parameters obtained through training use these parameters to establish predictive models, by randomly selected group to verify the predicted effects of different bands on the model accuracy through three validation to evaluate the robustness of this modeling approach. Use correlation analysis to verify the actual value of the sample and comparing the predicted value derived model predictive accuracy, validated (Table 1) shows that, by choosing different canopy spectral bands and select different parameters to establish the accuracy of the prediction model is not same ${ }^{[19-22]}$, table 1 shows when the selected band is 700 900nm when the predicted value and the actual value of the correlation coefficient of 0.9434 , and the root mean square (RMSE) reached 0.623 , a good prediction.

Table 1. Verify the accuracy of the model under different bands and different parameters

\begin{tabular}{cccc}
\hline Selected wave & C\&Gama(g) & RMES & r \\
\hline
\end{tabular}




\begin{tabular}{llll}
\hline $700 \sim 900 \mathrm{~nm}$ & $\begin{array}{l}\mathrm{C}=0.0039 \\
\mathrm{~g}=0.0039\end{array}$ & 0.623 & 0.9434 \\
$325 \sim 1075 \mathrm{~nm}$ & $\begin{array}{l}\mathrm{C}=0.0039 \\
\mathrm{~g}=3.0314\end{array}$ & 0.583 & 0.6377 \\
$325 \sim 1075 \mathrm{~nm}$ & $\begin{array}{l}\mathrm{C}=0.0125 \\
\mathrm{~g}=0.0078125\end{array}$ & 0.512 & 0.833 \\
\hline
\end{tabular}

\section{Discussion}

The study found that the incidence of wheat canopy spectra with the severity of the disease exhibit regular changes, by the onset extent, wheat plant canopy leaves contain chlorophyll, water, nitrogen content and the cell structure of wheat leaves are changing, the absorption and reflection of light changes regularly . Wheat canopy spectral reflectance with increasing wheat take-all disease showed a downward trend, particularly significant changes in the 700 900nm wavelength range, can be clearly observed spectral curve. The relationship between the use of the spectral curve and disease severity, the establishment of disease level monitoring model based on spectral image analysis capable of predicting the incidence of rapid and efficient wheat, can lay the foundation for large-scale predicted all disease of wheat .

Because the sample size of the data in this study is not large enough to take, so this sample through the analytical processing forecasting model to predict, or have a certain bias. Therefore, the need for further data collection more samples for training model to improve prediction accuracy. Meanwhile, the data collected from the handheld spectrometer derived little effect other surface features of the spectrum, but hyperspectral remote sensing image contains a wealth of information, so that in the future this method for remote sensing image analysis and processing, the need for further spectral image noise reduction, and the SVM algorithm optimization, select the optimal parameters in order to reduce the impact of other surface features of the spectrum, to improve prediction accuracy.

\section{Conclusions}

Showing between Wheat Take-all disease and wheat canopy spectral reflectance changes regularly, canopy spectral reflectance with disease exacerbation showed a decreasing trend, Particularly in the near infrared $(700 \sim 900 \mathrm{~nm})$ bands, the spectral reflectivity is particularly evident. So you can observe the wheat canopy spectral reflectance curves situation to determine the extent of the incidence of all disease of wheat. A prediction model based on these studies corresponding diseases, including the highest accuracy using the model 700 900nm wavelength band established as sensitive and can identify the model as the best of Wheat Take-all disease.

In this study, we using support vector machine approach to establish a model to identify Wheat Take-all disease. Because the support vector machine technology with high efficiency in a small sample of the training and multi-dimensional data 
processing, forecasting precision characteristics, and for this method on Wheat Takeall pest identification lay some foundation.

\section{Acknowledgment}

Funds for this research was provided by the National Natural Science foundation of China (31301604), Henan Science and technology plan (122102110045).

\section{References}

[1]Liu Xiu-ying, ZANG Zhuo, SUN Hua, LIN Hui. Discrimination of Cunninghamia lanceolata and Pinus massoniana based on hyperspectral data. Journal of Central South University of Forestry \& Technology. 2011(11):30-33.

[2]XIU Li-na, LIU Xiang-nan, LIU Mei-ling. Analysis and Modeling of Hyperspectral Singularity in Rice under Cd Pollution. Spectroscopy and Spectral Analysis. 2011(01):01920196.

[3]WANG Hai-guang, MA Zhan-hong, WANG Tao, CAI Cheng-jing, AN Hu, ZHANG Lu-da. Application of Hyperspectral Data to the Classification and Identification of Severity of Wheat Stripe Rust. 2007(09):1811-1844.

[4]LIU Bo, FANG Jun-yong, LIU Xue, ZHANG Li-fu, ZHANG Bing, TONG Qing-xi. Research on Crop-Weed Discrimination Using a Field Imaging Spectrometer. Spectroscopy and Spectral Analysis. 2010(07):1830-1833.

[5]LI Wei-guo, ZHAO Chun-jiang, WANG Ji-hua, LIU Liang-yun, SONG Xiao-yu. Monitoring the Growth Condition of Winter Wheat in Jointing Stage Based on Land Sat TM Image. Journal of Triticeae Crops. 2007.27(3):523-527.

[6]ZHANG Dong-yan, ZHANG Jing-cheng, ZHU Da-zhou, WANG Ji-hua, LUO Ju-hua, ZHAO Jin-ling, HUANG Wen-jiang. Investigation of the Hyperspectral Image Characteristics of Wheat Leaves under Different Stress. Spectroscopy and Spectral Analysis. 2011(04):1101-1105.

[7]HUANG Mu-yi, HUANG Wen-jiang, LIU Liang-yun, HUANG Yi-de, WANG Ji-hua, ZHAO Chun-jiang, Wan An-min. Spectral reflectance feature of winter wheat single leaf infected with stripe rust and severity level inversion. Transactions of the CSAE. 2004.20 (1):176-180.

[8]CHEN Wei, YU Xu-chu, ZHANG Peng-qiang, WANG Zhi-chao, WANG He. Object recognition based on one-class support vector machine in hyperspectral image. Journal of Computer Applications. 2011(08):02092-02096.

[9]QIAO Hong-bo, CHENG Deng-fa, SUN Jing-rui, TIAN Zhe, CHEN Lin, LIN Fu-rong. Effects of wheat aphid on spectrum reflectance of the wheat canopy. PLANT PROTECTION. 2005.31(2):21-26.

[10]WANG Zhi-hui, DING Li-xia. Tree Species Discrimination Based on Leaf-Level Hyperspectral Characteristic Analysis. Spectroscopy and Spectral Analysis. 2010.30(7):1825-1829.

[11]TAN Kun, DU Pei-jun. hyperspectral remote sensing image classification based on support vector machine.J.InfraredMillim. Waves.2008(2):0123-0128.

[12]DENG Rui, MA Yong-jun, LIU Yao-meng. Support Vector Machine Multi-class Classification Based on an Improved Cross Validation Algorithm. Journal of Tianjin University of Science \& Technology. 2007(06):0058-0061. 
[13]FENG Guo-he. Parameter optimizing for Support Vector Machines classification. Computer Engineering and Applications. 2011.47(3):123-124.

[14] ZHANG Xue-Gong. Introduction statistical learning theory and support vector machines [J]. Act Automatica Sinica. 2000.1(26):32-42.

[15]LI Xiao-yu, ZHANG Xin-feng, SHEN Lan-sun. A Selection Means on the Parameter of Radius Basis Function. Acta Electronica Sinica. 2005(12A):2459-2463.

[16]DU Pei-jun, LIN Hui, SUN Dun-xin. On Progress of Support Vector Machine Based Hyperspectral RS Classification. Acta Geodaetica Et Cartographica Sinica. 2006(12):00370040.

[17]DENG Wei, ZHANG Lu-da, HE Xiong-kui, Mueller J, ZENG Ai-jun etc. SVM-Based Spectral Recognition of Corn and Weeds at Seedling Stage in Fields. Spectroscopy and Spectral Analysis. 2009(7):1906-1910.

[18]MA Xin-lu, REN Zhi-yuan, WANG Yong-li. Research on Hyperspectral Remote Sensing Image Classification Based on SVM. System Sciences And Comprehensive Studies In Agriculture. 2009(2):0204-0207.

[19]LV Jie, LIU Xiang-nan. Hyperspectral Remote Sensing Estimation Model for Cd Concentration in Rice Using Support Vector Machines. Journal Of Applied SciencesElectronics Information Engineering. 2012(01):0105-0111.

[20]A.-K.Mahlein, T.Rumpf, P.Welke, H.-W.Dehne, Plumer, U.Steiner, E.-C.Oerke. Development of spectral indices for detecting and identifying plan diseases. Remote Sensing of Environment. 2013(128):21-30.

[21]Minghua Zhang, Zhihao Qin, Xue Liu, Susan L.Ustin. Detection of stress in tomatoes induced by late blight disease in California, USA, using hyperspectral remote sensing. International Journal of Applied Earth Observation and Geoinformation. 2003(4):295-310.

[22]Chanseok Ryu, Masahiko Suguri, Mikio Umeda.

Multivariate analysis of nitrogen content for rice at the heading stage using reflectance of airborne hyperspectral remote sensing.Field Crops Research. 2011(122):214-224. 